\title{
Discussion on Linkage between Basic Courses and Professional Courses in Product Design Teaching
}

\author{
Xiangli Lu \\ Eastern International Art College \\ Zhengzhou University of Light Industry \\ Zhengzhou, China
}

\begin{abstract}
The linkage between basic courses and professional courses is important in the current product design teaching. How to make students clear the role of basic courses in professional courses when they are studying these basic courses and further make application and reflection in the professional courses, and drive students to further enhance their innovation and design abilities is the problem to be solved mainly in the current product designs teaching. This paper made analysis and discussion on the adjustment of the existing curricula and the setting of linked curricula, and made experimental verification with educational practice, trying to find a way to improve the linkage between basic courses and professional courses.
\end{abstract}

Keywords-basic; professional; linkage

\section{INTRODUCTION}

Currently, the professional courses of product design is set mainly according to the teaching framework of basic curricula - professional curricula", and the basic curricula will be divided into many small units in college grades 1 and 2, with appropriate courses to achieve the teaching task of each unit, to make students have the abilities necessary for professional design. When entering the third and fourth grade, students are required to have certain design ability, enabling to deal with the design of various topics in multiple professional courses and make reasonable solution to some design problems, so as to make them have the ability to independently complete design projects. After four years of study, students will have ability to deal with the related design tasks of the major and exert their professional expertise on their job. In fact, this is also the teaching goal of all design schools to want to achieve, but real situation is not satisfying. As a teacher of design, I have acted teaching tasks of both basic courses and professional courses and find many problems in teaching, especially in the transition from basic courses to professional courses and the linkage between them, which is also one of important problems in the current product design.

\section{The Problems Highlighted IN THE LiNKAGE}

\section{BETWEEN BASIC COURSES AND PROFESSIONAL COURSES}

The current teaching of basic courses generally only focuses on the basic contents of courses and the professional design is hardly involved. These knowledge and methods are extracted from the design, relatively independent, and it is very difficult for the students who just learn the introduction to college design and only have foundational drawing training to fully comprehend these courses, which have become the troubles of many students in studying professional courses. Taking the "three major components" of basic courses as example, we can find most colleges and universities set these contents in the college freshman year, and the "three major components" is the important part of foundational teaching and takes a large proportion of foundational teaching hours, more than the class hours of any other basic courses. other basic courses, such as basic sketches, performance techniques, mechanical drawing and other courses will be involved in the further whole professional courses, so these skills can get training and promotion, but the "three major components" of basic course is difficult to have a direct linkage with professional courses. From the teaching reflection, many students don't clear the concept of "components" and do not know how to use basic elements to form new shape and moulding, meanwhile they have some doubts, such as "what is the good after learning" and "how to use them in the future", so that students hardly link their such learning with the professional contents when they begin to study the professional courses, and the basic course can not play its foundational roles.

Students can not comprehend the position and roles of each course in the whole curriculum system in their study of basic course, and they have scattered knowledge points and are not able to constitute a systematic knowledge chain after their study completion. The basic course of professional itself forms a relatively closed system, lack of internal linkage with the design course of professional, and the foundation out of link is obvious in the curriculum content, topic type and training methods. At the same time, the branch courses and unit courses in the course group are also separated, lack of linkage. There is no specific requirement for the quantity and quality of foundation of professional design, no real recognition and scientific explanation of educational standard, such as understanding, familiarizing, mastering, can, will, enough, skilled. Therefore, such a teaching effect is produced that students are not able to integrate their learning into an entire knowledge structure.1

Due to the above, students often get bewildered when entering a higher level of professional design course. They

CLC: J527 Document code: A 
are still lack of knowledge in the expression of design thinking, the color arrangement, modeling and others necessary for the design, and are not able to achieve mastery through a comprehensive study of the mechanical drawing, materials technology, design performance and other skills training, not sum up performance through good combination of design task. They still need teachers' direction step by step and they may still have many problems unsolved. The students' deficiency of basic knowledge and ability in a link, will certainly impact the subsequent design curriculum and students' design career in the future, which also reflects the teaching of basic courses have some problems. Thus, the effective linkage between basic courses and professional courses has become an important problem that the teachers of product design must think about immediately.

\section{IN ORDER TO SOLVE THE ABOVE PROBLEMS, FROM THE PERSPECTIVES OF CURRICULUM PROVISION AND} Adjustment, THE Author Thinks We CAN SET ABout FROM THE FOLLOWING ASPECTS

\section{A. Build Systematic Course System}

The relationships of knowledge points between different basic courses are not close, such as mechanical drawing and expression methods, plane composition and three dimensional composition, etc. In teaching process, the teacher should find the relationship between them and let students clearly understand its role in designing curriculum to form systematic frame system; make good cohesion and transition of knowledge between plane composition and three dimensional composition, pay more attention to the transform "from the plane to the three dimensional", and train students' ability in three-dimensional modeling and the consciousness of multi-perspective observation to make students get effective training of form modeling and thinking method.

Even though they cannot establish systematic frame system, they should clarify the relationships between different units of the basic course system and make adjustments. Except for completing the teaching and training of basic knowledge, they should strengthen the explanation and learning of cases and use cases to answer questions such as "what can we benefit from learning it" and "how to use it in the future", to make students can establish relationships between the basic and the professional.

\section{B. Integrate Professional Contents in Basic Courses}

Because of the development and division of industry, the design has been divided into many categories. Different majors have different requirements for the teaching contents of basic courses. The emphasis of basic course of modeling of some majors such as visual communication design, environmental art design and product design is different. The design objects of the major of visual communication design often present in two-dimensional way and pay more attention to the organization and composition of two-dimensional modeling; because the design objects of environmental art design and product design often present in three-dimensional and real way, they pay more attention to the shape of three- dimensional modeling. In terms of two majors of environmental art design and product design that have the three-dimensional characteristics, the teaching contents of them should be different as well.

The author has engaged in the teaching of three dimensional composition of product design for many years and thinks that it will suit the characteristics of the major to properly integrate professional contents in the course. For example, in the shape of three-dimensional form, namely the composition of the line, the author requires students to use linear materials to shape a daily supply in our life. In the process of form shaping, students should consider the property and characteristics of the material and pay attention to the expression of beauty in form. Meanwhile, it requires the form should have the using function of daily supplies. It is proved by several years of teaching practice that this method is effective. Students expand their abilities in thinking expression through training. The body shaped by them has appropriate function as well as pays attention to the expression of overall beauty in form. It makes the purpose and direction of learning become clearer. By depending on linear materials, students can let the works present proper function and form. It transforms the assignments from pure form to professional application, fades the boundary between the basic and the professional and makes the relationship between basic course and professional course become closer.

\section{Set Transitional Courses}

Because the courses in college grades 1 and 2 have large amount of information and most of them are basic courses and the content of each course is relatively independent and cannot be completely embodied in one system, students often don't understand the situation, only pay attention to the learning of the course without understanding the interactions and relationships between these courses, let alone "gather parts into a whole".

After students enter into the period of professional design in senior grades, teachers pay more attention to teach the knowledge and contents of special topics, and often use the forms of task or design project to carry out the course training. It requires students have solid basic skills, including the grasp of thinking method of design and basic skills and can flexibly apply then to the tasks. In terms of the students, before they absorb and digest the knowledge and skills learned in the past two years, it is a little difficult for them to continue the new learning and connect all the knowledge and apply them. With the continuous deepening of tasks, students who master very well can keep up with the pace, while the other part of students who have a smattering of knowledge can only explore in this process, some students are even confused about the tasks when they graduate. Many professional teachers also have the same opinion on this problem.

Therefore, it is very necessary to set a transitional course between the basic course and the professional course to help students to understand and digest the knowledge learned in the past two years. This course plays the role of serving as a link between the basic courses and the professional course. 
On one hand, students can review and systemize basic knowledge and consolidate basic skills; on the other hand, they can have relatively systematic and comprehensive understanding for the follow-up professional courses. In this course, students have the opportunity to anew integrate the units in basic courses, clarify the function of them in professional courses and try to use them in tasks to strengthen the links between basic course and professional course.

\section{Review Basic Courses in Professional Design Course}

As mentioned above, many knowledge and skills in basic courses are inevitably used in professional design, so basic course cannot separate from professional course. It serves professional course and develops with the development of professional course. Professional course also depends on basic course. When teachers teach the professional design, they should properly review the basic, know the situation that students grasp the basic courses, understand the contents and effects of basic teaching and appropriately supplement students' deficiencies.

\section{PRACTICE of Transitional CoURSE}

The author is a teacher of specialized course in the product teaching and research office and has the opportunity to do practical teaching according to the above views. It can be implemented in the course of Procedure and Method of Product Design opened in the fourth semester after students finish the learning of basic courses. The teaching contents of this course are mainly the procedure and method of general product design. The teacher integrates basic knowledge and skills in this course. The teaching objectives of this course are to let students preliminarily know about the product design, grasp the basic procedure of product design, meanwhile master the thoughts and methods of product design and have the ability to correctly express their conceptions and independently complete the design.

Design is the process to transform problems to clear design direction. The thinking gradually becomes clear from the ambiguous by passing many stages such as task discussion, market survey, user study, research analysis, design positioning, and design concept, scheme evaluation, scheme determination, mechanical drawing, threedimensional expression, page layout and model making. There is curriculum knowledge that has been taught and new knowledge points in these stages. Especially for the part of design concept, it is necessary to pay attention to deep thinking on materials and techniques, product structure, function and design expression. This course focuses on solving problems in the cohesion of many knowledge points and design of system.

The course is started from a task and can be divided into four stages such as the preparation of design, the implementation and determination of design, and the production and promotion of design. In the process of the whole design, the teacher should pay attention to the infusion of new knowledge as well as periodic tests of knowledge points learned before, supplement the parts that students are weak in and strengthen the training to ensure the complete cohesion of knowledge chain.

Through this kind of complete and systematic cohesion, students can understand the position and role of basic course in professional course. The procedure for teachers to integrate in the knowledge points can also make students grasp the procedure and method of product design as well as connect various knowledge and abilities to combine them into complete system to smoothly implement the subsequent tasks.

The above are practical situations faced by the author in the teaching processes of basic courses and professional courses. The author tries to analyze and discuss from aspects of adjusting the original courses and setting transitional tasks, verifies through teaching practice and seeks for the ways to improve the problems appeared in the cohesion of basic courses and professional courses.

\section{REFERENCES}

[1] Wu Lieyan. Research on Professional Basic Courses of Major of Art and Design [D/O], doctoral thesis of Nanjing University of the Arts, CNKI, 2001, P29-31

[2] Shi Ying, Pan Ying, Yu Lu. Teaching Research and Practice on Form Composition Series in Basic Course of Building Design [D], Huazhong Architecture, 2009(1)

[3] Shen Guandong. Reasonable Construction of Basic Course System of Art and Design, Anhui Literature [J], 2007(12) 